Published in final edited form as:

Bone Marrow Transplant. 2015 March ; 50(3): 402-410. doi:10.1038/bmt.2014.280.

\title{
Baseline body mass index among children and adults undergoing allogeneic hematopoietic cell transplantation: clinical characteristics and outcomes
}

\author{
Michael Gleimer ${ }^{1}$, Yumeng $\mathrm{Li}^{2}$, Lawrence Chang ${ }^{3}$, Sophie Paczesny ${ }^{4}$, David A. Hanauer ${ }^{5,6}$, \\ David G. Frame ${ }^{7}$, Craig A. Byersdorfer ${ }^{3}$, Pavan R. Reddy ${ }^{8}$, Thomas M. Braun ${ }^{2}$, and Sung \\ Won $\mathrm{Choi}^{3}$ \\ ${ }^{1}$ University of Michigan Medical School, University of Michigan, Ann Arbor, MI, USA \\ ${ }^{2}$ Department of Biostatistics, University of Michigan, Ann Arbor, MI, USA \\ ${ }^{3}$ Department of Pediatrics, Division of Pediatric Hematology/Oncology, Blood and Marrow \\ Transplantation Program, University of Michigan, Ann Arbor, MI, USA \\ ${ }^{4}$ Department of Pediatrics, Indiana University School of Medicine, Indianapolis, IN, USA \\ ${ }^{5}$ Department of Pediatrics, Division of General Pediatrics, University of Michigan, Ann Arbor, MI, \\ USA \\ ${ }^{6}$ Informatics Core of the Comprehensive Cancer Center, University of Michigan, Ann Arbor, MI, \\ USA \\ ${ }^{7}$ College of Pharmacy, University of Michigan, Ann Arbor, MI, USA \\ ${ }^{8}$ Department of Internal Medicine, Division of Hematology/Oncology, Blood and Marrow \\ Transplantation Program, University of Michigan, Ann Arbor, MI, USA
}

\section{Abstract \\ Obesity is an important public health problem that may influence the outcomes of hematopoietic cell transplantation (HCT). We studied 898 children and adults receiving first-time allogeneic hematopoietic stem cell transplants between 2004 and 2012. Pre-transplant body mass index (BMI) was classified as underweight, normal weight, overweight, or obese using the WHO classification, or age-adjusted BMI percentiles for children. The study population was}

\footnotetext{
Corresponding Author: Sung Won Choi, M.D., M.S. Department of Pediatrics, Division of Hematology/Oncology, University of Michigan 1500 East Medical Center Drive, Medical Professional Building, D4118, SPC 5718 Ann Arbor, MI, 48109-5718, USA Phone: 734-615-5707 Fax: 734-615-0464 sungchoi@umich.edu.

AUTHORSHIP

M.G. collected and analyzed data, and drafted and approved the manuscript; Y.L. analyzed data and approved the manuscript; L.C. collected and analyzed data, and approved the manuscript; S.P. conducted scientific analyses and approved the manuscript; D.A.H. collected data and approved the manuscript; D.F. collected and analyzed data and approved the manuscript; C.B. cared for patients and approved the manuscript; P.R. designed the study, cared for patients, and approved the manuscript; T.B. designed the study, analyzed data, and approved the manuscript; S.W.C. designed the study, cared for patients, collected and analyzed data, and drafted and approved the manuscript.

CONFLICT OF INTEREST STATEMENT

The authors declare no potential conflict of interest.

Supplementary information is available at the journal's website.
} 
predominantly Caucasian, and the median age was 51 years ( 5 months -73 years). The cumulative 3-year incidence of non-relapse mortality (NRM) in underweight, normal weight, overweight, and obese patients was 20\%,19\%,20\%, and 33\%, respectively. Major causes of NRM were acute and chronic graft-versus-host disease (GVHD). The corresponding incidence of relapse was 30\%, $41 \%, 37 \%$, and $30 \%$, respectively. Three-year overall survival was $59 \%, 48 \%, 47 \%$, and $43 \%$, respectively. Multivariate analysis showed that obesity was associated with higher NRM (HR 1.43, $\mathrm{p}=0.04$ ), and lower relapse (HR 0.65, $\mathrm{p}=0.002$ ). Pre-transplant plasma levels of ST2 and TNFR1 biomarkers were significantly higher in obese compared with normal weight patients ( $\mathrm{p}=0.04$ and $\mathrm{p}=0.05$, respectively). The increase in NRM observed in obese patients was partially offset by lower incidence of relapse with no difference in overall survival.

\section{Keywords}

body mass index; obesity; outcomes; hematopoietic cell transplantation

\section{INTRODUCTION}

Overweight or obesity is a complex, multifactorial chronic disease that arises from social, behavioral, economic, cultural, physiological, and genetic factors (1). The prevalence of overweight and obesity has increased substantially since the 1960s, resulting in a broad range of health problems and economic consequences (2-5). An estimated 1.4 billion adults (ages 20 and older) worldwide are overweight or obese, with an additional 170 million overweight or obese children and adolescents, one quarter of whom are under the age of five $(6,7)$. Evidence-based research has demonstrated the relationship between obesity and high blood pressure, elevated cholesterol, type 2 diabetes, stroke, congestive heart failure, coronary heart disease, osteoarthritis, sleep apnea and respiratory problems, as well as various cancers (2). As such, overweight and obesity place individuals at very high risk for morbidity and mortality (8).

In the allogeneic hematopoietic cell transplantation (HCT) setting, pre-transplant comorbidities have shown prognostic association with acute graft-versus-host disease (GVHD) and subsequent mortality (9). The HCT comorbidity index (HCT-CI) is a tool that assigns a pre-transplant score for various organ dysfunctions, including pulmonary, hepatic, cardiac, and renal comorbidities $(10,11)$. Obesity is also included as one of the comorbidities, and a score is assigned based on BMI $>35 \mathrm{~kg} / \mathrm{m}^{2}$ in adults or BMI for age of the $95^{\text {th }}$ percentile or higher in children. While the role of obesity as an independent risk factor on allogeneic transplant outcomes, such as GVHD, relapse, non-relapse mortality (NRM), and overall survival, has been previously explored by several groups, inconsistencies have been reported depending on the study population (12-24). Recently, plasma biomarkers predictive of GVHD and NRM have been identified (25-27). However, none of these studies examined biomarkers according to BMI categories.

In the present study, we measured pre-transplant BMI of pediatric and adult patients undergoing allogeneic HCT. Based on the greater risk for morbidity and mortality in overweight and obesity, we hypothesized that allogeneic HCT recipients with increased pre- 
transplant BMI would have high risk of GVHD and NRM, resulting in inferior overall survival, compared with normal weight patients. The study design included a retrospective cohort analysis of allogeneic HCT patients and their outcomes stratified by BMI at a single institution over a 9-year study period. Plasma biomarkers were also measured in patient samples prospectively and compared across BMI categories relative to normal weight patients.

\section{MATERIALS AND METHODS}

\section{Literature review}

We used PubMed/MEDLINE and Google Scholar to identify previously published peerreviewed articles on the risk of BMI in outcomes after allogeneic HCT. The search was restricted to studies published in the English language between January 1994 and May 2014. We applied the following MeSH terms in the search: ('obesity,' OR 'overweight' OR 'body mass index') AND ('stem cell transplant' OR 'bone marrow transplant'). The initial search yielded 23 manuscripts. Ten were excluded immediately, because they contained either autologous (9) or syngeneic (1) transplants. Two co-authors (MG and SWC) read the full text of the 13 remaining papers. Table S1 summarizes key outcomes from each of the studies.

\section{Definition of body mass index (BMI)}

BMI was calculated as weight (kilograms) divided by height (meters) squared (28). The index was used either as a categorical variable, to evaluate hazard ratios (HR) and 95\% confidence intervals (CI). For adult patients (ages $\geq 18$ years), the categories were defined according to the WHO (29): underweight (BMI $<18.5 \mathrm{~kg} / \mathrm{m}^{2}$ ), normal weight (BMI $18.5-$ $24.9 \mathrm{~kg} / \mathrm{m}^{2}$ ) overweight (BMI $25.0-29.9$ ) and obese (BMI $\geq 30.0 \mathrm{~kg} / \mathrm{m}^{2}$ ). For children and adolescents (ages < 18 years), age-adjusted BMI were compared with the CDC BMI for age group charts to obtain percentile rankings. Categories were defined as previously described (30): underweight (BMI $<5^{\text {th }}$ percentile), normal weight (BMI $5^{\text {th }}-84.9^{\text {th }}$ percentile), overweight (BMI $85^{\text {th }}-94.9^{\text {th }}$ percentile), and obese (BMI $\geq 95^{\text {th }}$ percentile).

\section{Study design}

A retrospective cohort study was conducted of 988 consecutive allogeneic HCT performed between January 1, 2004 and December 31, 2012. The study was approved by the University of Michigan Institutional Review Board (IRB). Only first-time allogeneic HCT were included; forty-one patients with prior allogeneic transplants were therefore excluded. Fiftysix patients who received umbilical cord blood transplants were excluded a priori to reduce potential confounding. The total study population was 898 patients. Height and weight information, documented within two weeks prior to the transplant procedure (day 0), was retrieved from the University of Michigan's electronic health record (EHR). The BMI was computed for each individual, as described above. Outcomes of the study included overall survival and the cumulative incidences of acute and chronic GVHD, NRM, and relapse. 


\section{Demographics and transplant characteristics}

Demographics, including age at transplant, gender, race, ethnicity, disease at transplant, and number of prior autologous transplants were collected for each patient and recorded in the integrated University of Michigan Blood and Marrow Transplantation (BMT) Clinical Research Database and Repository. Transplant data, including donor stem cell source, donor type (related or unrelated), donor gender, human leukocyte antigen (HLA) matching, cytomegalovirus status of donor and recipient at transplant, $\mathrm{ABO}$ and $\mathrm{Rh}$ blood types of donor and recipient, conditioning regimen, $\mathrm{CD} 34^{+}$cell dose infused for transplant, GVHD prophylaxis regimen, acute and chronic GVHD, time to engraftment, and comorbidity scores (low, intermediate, or high) according to the HCTCI (11) were also collected and recorded. Granulocyte colony-stimulating factor was started on day 6 to promote neutrophil engraftment, which was defined as the first of three consecutive days with absolute neutrophil count $\geq 500 / \mathrm{mm}^{3}$.

\section{Electronic Medical Record Search Engine (EMERSE): chart review}

Data abstraction of the above transplant variables was supported by the use of the University of Michigan EMERSE, as previously described (31). A script was also devised to extract the latest available pre-transplant weight and height for the study population. These values were inspected (MG and SWC) to ensure that they were measured within 14 days of the transplant procedure.

\section{Plasma biomarkers}

Pre-transplant blood samples were collected prospectively from allogeneic HCT patients between January 2004 and May 2010, with informed consents and in agreement with the Declaration of Helsinki. Samples were collected in heparin-containing Vacutainer tubes (Becton Dickinson, Franklin Lakes, NJ, USA) and underwent Ficoll (Amersham, Piscataway, NJ, USA) gradient centrifugation to separate the plasma. Plasma concentrations of suppression of tumorigenicity 2 (ST2), tumor necrosis factor receptor 1 (TNFR1), and interleukin 2 receptor alpha (IL2Ra) were measured in duplicate using enzyme-linked immunosorbent assays (ELISA) according to the manufacturer's protocol (R \& D Systems, Minneapolis, MN, USA), as previously described (25-27, 32). Absorbances were read using a SpectraMax M2e plate reader (Molecular Devices, Sunnyvale, CA, USA). The integrated BMT Clinical Research Database and Repository, which contained demographic and transplant characteristics, as well as the clinical outcomes (GVHD, NRM, relapse, and survival), was linked to plasma biomarker samples that were collected and stored in accordance with IRB-approved protocols.

\section{Statistical analysis}

Demographics of all first-time allogeneic HCT patients who received bone marrow (BM) or peripheral blood stem cell (PBSC) grafts were summarized. Counts and percentages were determined for categorical variables. Medians and ranges were determined for continuous variables. Cumulative incidences with competing risks were determined using the methods of Fine and Gray (33) and compared using the test described by Gray (34). Overall survival was compared using the Kaplan-Meier method (35). Differences in characteristics between 
patient groups were assessed with the Kruskal-Wallis test for continuous variables and the $\chi^{2}$ test of association for categorical values. Differences in the distribution of baseline plasma biomarker levels among categories of BMI were assessed with the Kruskal-Wallis test. Multivariate analysis incorporating possible confounders (age, malignant vs. nonmalignant diagnosis, related vs. unrelated donor, HLA match vs. mismatch, BM vs. PBSC transplant, full vs. reduced intensity conditioning, transplant 2004-2008 vs. 2009-2012) while examining the association of BMI with acute and chronic GVHD, NRM and relapse were assessed with competing risks regression (33), and with overall survival using Cox regression. Data were analyzed using R version 2.15.02 (GNU General Public License). Statistical significance was defined as a p-value less than 0.05 .

\section{RESULTS}

\section{Patient and transplant characteristics of the study population}

The median age of the study population was 51 years (range 5 months -73 years, interquartile range [IQR] $31-58$ years), comprised predominantly of adults ( $\geq 18$ years old, $89 \%$ ), males (60\%), and Caucasians (92\%). Thirty-four percent of the population was categorized as obese, $32 \%$ as overweight, $32 \%$ as normal weight, and $2 \%$ as underweight, with a median BMI of $26.9 \mathrm{~kg} / \mathrm{m}^{2}$ (Table 1). The combined prevalence of pre-transplant overweight and obesity increased from 58\% in 2004 to $69 \%$ in 2012, an average increase of approximately $1.2 \%$ per year. The frequency of intermediate or high comorbidity index (HCT-CI) was greatest in overweight and obese patients (Table 1).

Ninety-four percent of patients had hematological malignancies. Patients received HLAmatched related $(47 \%)$, mismatched related $(3 \%)$, matched unrelated $(38 \%)$, or mismatched unrelated transplants (12\%). HCT was performed using cells from peripheral blood (PB, $85 \%$ ) or bone marrow (BM, 15\%). Sixty-one percent of patients were conditioned with myeloablative regimens (of these, $20 \%$ included total body irradiation [TBI] $\geq 1200 \mathrm{cGy}$ ), and 39\% with reduced intensity regimens, according to the ASBMT working definitions (36). Six percent were conditioned with regimens that involved anti-human $\mathrm{T}$ cell antibody (ATG/thymoglobulin or alemtuzumab). $\mathrm{CD} 34^{+}$cells were infused at a median concentration of $5.5 \times 10^{6}$ cells $/ \mathrm{kg}$ (range $1.1 \times 10^{6}-1.75 \times 10^{7}$, IQR $4.6 \times 10^{6}-6.9 \times 10^{6}$ ). Engraftment occurred on median day 12 (range $5-28$, IQR $11-13$ ). Fifty-five percent of transplants were performed between 2004 and 2008, and 45\% between 2009 and 2012 (detailed characteristics are presented in Table 1).

\section{Non-relapse mortality}

The cumulative incidence of 3-year NRM in our population was $24 \%$, and according to BMI categories (underweight, normal weight, overweight, and obese) was $20 \%, 19 \%, 20 \%$, and $33 \%$, respectively (Figure 1A). Across BMI categories, obese patients were at greater risk of NRM at 3 years compared with normal weight patients (HR 1.43, 95\% CI 1.02-2.01, $\mathrm{p}=0.04$, Table 2). Other variables significantly associated with increased NRM in the multivariate analysis were unrelated donor $(\mathrm{p}<0.001)$, PBSC as transplant source $(\mathrm{p}=0.002)$, and HLA mismatch ( $\mathrm{p}=0.004)$ (Table 2). The major causes of NRM were acute GVHD (40\%) and chronic GVHD (45\%) (Table 3). 


\section{Graft-versus-host disease}

The cumulative incidence of grade $2-4$ acute GVHD in the study population at day 100 was $37 \%$. According to BMI categories (underweight, normal weight, overweight, and obese), the incidences were $40 \%, 33 \%, 37 \%$, and $41 \%$, respectively. In adjusted models, categorical BMI (Table 2) was not significantly associated with acute GVHD. Variables significantly associated with acute GVHD in the multivariate analysis were unrelated donor $(\mathrm{p}<0.001)$, PBSC as transplant source $(\mathrm{p}=0.04)$, HLA mismatch $(\mathrm{p}<0.001)$, and transplant before 2009 ( $\mathrm{p}=0.02)$ (Table 2).

The cumulative incidence of chronic GVHD at 3 years was $46 \%$, which was greatest in obese patients (50\%), followed by overweight, normal weight, and underweight $(46 \%, 42 \%$, and 40\%, respectively) (Figure 1B). After controlling for potential confounders, however, BMI as a categorical variable was not associated with risk of chronic GVHD. There were no other variables that significantly predicted the risk of chronic GVHD (Table 2).

\section{Relapse}

The cumulative incidence of relapse in the study population at 3 years was $36 \%$. Based on BMI groups (underweight, normal weight, overweight, and obese), the incidences were $30 \%, 41 \%, 37 \%$, and 30\%, respectively (Figure 1C). In the adjusted models, obese patients experienced significantly decreased relapse when compared with normal weight patients (HR 0.65, 95\% CI $0.49-0.86, \mathrm{p}=0.002$, Table 2). Other variables associated with relapse in the multivariate analysis included malignant disease $(\mathrm{p}=0.002)$, related donor $(\mathrm{p}<0.001)$, and transplant date before $2009(\mathrm{p}=0.02)$ (Table 2).

\section{Overall survival}

The 3-year overall survival of our study population was $46 \%$, with the poorest survival outcome of $43 \%$ in obese patients compared with 59\%, 48\%, and 47\% in the other BMI categories (underweight, normal weight, and overweight, respectively) (Figure 1D). However, in adjusted models, categorical BMI revealed no significant association with survival. Variables found to be associated with decreased overall survival included patient age $(\mathrm{p}=0.003)$, unrelated donor $(\mathrm{p}=0.02)$, PBSC as transplant source $(\mathrm{p}=0.003)$, HLA mismatch $(\mathrm{p}=0.03)$, and transplant date before $2009(\mathrm{p}=0.01)$ (Table 2).

\section{Baseline levels of plasma biomarkers}

Pre-transplant plasma levels of pro-inflammatory biomarkers ST2, TNFR1 and IL2Ra were measured by ELISA in a subset of patients. The median ST2 concentration in obese patients $(257 \mathrm{pg} / \mathrm{ml}$, IQR $0-1045 \mathrm{pg} / \mathrm{ml})$ was significantly higher than in normal weight patients (131 pg/ml, IQR 0 - 628) ( $\mathrm{p}=0.04$, Table 4). Likewise, the median TNFR1 concentration was elevated in obese patients ( $2644 \mathrm{pg} / \mathrm{ml}$, IQR 1922 - 3395) compared with normal weight patients ( $2129 \mathrm{pg} / \mathrm{ml}, \mathrm{IQR} 1486-3232)(\mathrm{p}=0.05$, Table 5). The concentration of IL2Ra was not significantly different among BMI categories (data not shown). 


\section{DISCUSSION}

Obesity is a major public health problem worldwide $(7,29,37)$. The prevalence of obesity is rapidly rising, leading to serious social, health, and economic challenges $(1,2,38)$. In this study, we set out to investigate the impact of obesity on outcomes following allogeneic HCT, including GVHD, NRM, relapse, and overall survival. We found that our population was comprised of $34 \%$ obese patients, which was higher than expected based on the geographic locale of our institution; in 2011, Michigan ranked $10^{\text {th }}$ in USA among states with the highest prevalence of obesity at $31.1 \%$ in adults age 20 years and older (39). The $34 \%$ of obese patients in our study was striking, particularly because it was three-fold higher compared with the worldwide obesity estimate of $11 \%$ (7). This important finding highlights the growing number of patients with concomitant obesity who are being treated for lifethreatening hematological malignancies and undergoing high-risk allogeneic HCT.

Among allogeneic HCT recipients, the impact of obesity on outcomes remains controversial (12-24). Herein, BMI examined either as a categorical predictor did not significantly change the overall results and interpretations. After adjusting for other covariates, our findings provide evidence that obese patients experienced significantly increased NRM and decreased relapse, with no difference in overall survival compared with normal weight patients. While our study population was comprised predominantly of adults, these observations are concordant with a recent registry-based analysis of 3687 pediatric patients (age $2-18$ years) (12).

Obesity in solid organ transplantation has been shown to be associated with worse outcomes, including delayed graft function, graft failure, surgical site infection, cardiovascular disease, prolonged hospital course, and increased healthcare costs (40). Interestingly, our data show that obesity was associated with significantly decreased risk of relapse, in agreement with two large registry data studies $(12,20)$. By contrast, a singlecenter study of 325 children reported a higher incidence of relapse in obese patients (14), highlighting the challenges of comparing results across studies with heterogeneous populations. It is important to consider that BMI does not distinguish excess body fat from lean mass (41). Additionally, the pharmacokinetics and distribution of drugs in different tissues may vary across the range of BMI, and thereby impact outcomes (42). Alternatively, decreased relapse may not have been a direct result of excessive fat stores or obesity. For instance, the mechanisms underlying the increased frequency of chronic GVHD in obese patients may have offered protection against relapsed disease (graft-versus-leukemia effect) (43). It is also possible that our institutional practice of chemotherapy dose modifications according to adjusted ideal body weight compared with actual weight may have impacted the risk of NRM and relapse. The potential effects of these adjustments on outcomes are not well-understood. Further investigation is warranted to confirm the findings reported herein.

Obesity is strongly associated with metabolic abnormalities and likely mediated in part by a chronic inflammatory state induced by secretion of cytokines in the adipocytes, such as TGF- $\beta$, TNF- $\alpha$, IL-6, and angiotensinogen (44). We have previously shown that ST2, TNFR1, and IL2Ra can predict GVHD and NRM after allogeneic HCT (25-27). We were therefore interested in whether these biomarkers differed across a range of BMI. We found 
that obese patients had higher plasma levels of ST2 and TNFR1 at the time of transplant. ST2, a decoy receptor for interleukin-33 secreted by epithelial cells, endothelial cells, and fibroblasts in response to pro-inflammatory stimuli, biases $\mathrm{T}$ cells toward a $\mathrm{T}_{\mathrm{H}} 1$ phenotype, and its high levels are associated with acute GVHD, resistance to GVHD treatment, and NRM (27). TNFR1, a receptor and surrogate marker for TNFa, which is shed from the cell surface following ligand binding, is a significant predictor of GVHD and NRM (25). Elevated ST2 levels have previously been reported in serum and adipose tissue of obese humans (45), adipose tissue of diet-induced obese mice (45), and in the serum of rats fed a high-fat diet (46). TNFR1 is also present at an increased level in obese individuals (47), and can be lowered with exercise and weight loss (48). Our recapitulation of these findings in an HCT cohort may provide a basis for future studies of the molecular mechanisms linking obesity with transplant outcomes.

To our knowledge, this is the first study in HCT to measure baseline biomarkers and correlate them across BMI categories. Clearly, further investigation of these biomarkers is needed. Target-specific biomarkers that can help inform risks and outcomes in the HCT setting may assist in risk stratification for risk-adapted clinical trials. For instance, depending on the patient's pre-HCT disease characteristics, BMI, HCT-CI, and/or biomarkers levels, the transplant team may begin to stratify patients according to low-risk versus high-risk. The pathogenesis of GVHD involves a complex network of proinflammatory cytokines (25). Therefore, in the present study, it was not surprising that obese individuals with higher baseline levels of TNFR1 and ST2 were associated with increased risk of developing GVHD. Thus, future discovery of biomarkers in the early pre-HCT setting is warranted to better develop risk-adapted treatment strategies. Importantly, they may provide insight into the delicate balance between relapse and GVHD and NRM.

The current study was conducted over nearly a decade in 898 children and adults undergoing first-time allogeneic HCT, predominantly due to hematological malignancies. Strengths of the study included a large, heterogeneous population with an array of socio-demographic data, including patient age, underlying disease, stem cell source, and conditioning regimen, and the prospective evaluation of plasma biomarkers prior to transplant, allowing us to form generalized conclusions. At the same time, we recognize this heterogeneous patient population is also a limitation, precluding us from detecting associations that may have reached significance if potential confounders, such as age (pediatric vs. adult) or type of transplant (full vs. reduced intensity conditioning), were restricted. Nonetheless, we attempted to control for this by performing multivariate analyses with other covariates and with BMI modeled as both a categorical and continuous (data not shown) variable. Our results were largely unchanged by both these approaches. Furthermore, we performed a subgroup analysis of children $<18$ years of age and patients with acute lymphoblastic leukemia, acute myelogeneous leukemia, and myelodysplastic syndrome. Although the sample sizes were very small, we found no differences in outcomes (GVHD, NRM, relapse, and survival) between the overall study population and these sub-groups (Table S2). Clearly, future studies are needed with larger populations to address these effects along with considerations of race and ethnicity. Our patient population was primarily Caucasian with very few Asians, Hispanics, and Blacks, and we recognize that findings may differ across these populations. 
Additionally, other confounding factors, such as smoking and alcohol use, that may impact the association of body weight with mortality were not included in our analyses.

In conclusion, the current results showed increased NRM but decreased relapse in obese patients undergoing allogeneic HCT. To our knowledge, this study is the first to report significantly elevated pre-transplant levels of ST2 and TNFR1 among obese patients relative to normal weight patients. Our data argue for a well-designed prospective study that incorporates correlative laboratory analyses (25-27), which may improve our understanding of the impact of BMI on transplant outcomes (11). While obesity is an important risk factor for development of other comorbid complications, such as hypertension, dyslipidemia, cardiovascular diseases, and diabetes mellitus, we recognize that the presence of these disturbances may vary widely among obese individuals. Nonetheless, obesity-related comorbidities should be routinely assessed and treated by appropriate specialists, working closely with the transplant team. Accordingly, explaining these risks could inform post-HCT expectations.

\section{Supplementary Material}

Refer to Web version on PubMed Central for supplementary material.

\section{ACKNOWLEDGEMENTS}

We are grateful to the patients, their families, and the clinical personnel who participated in this study. We thank the BMT Program Team at the Clinical Trials Office at the University of Michigan for data collection and management. MG was supported by the Student Biomedical Research Program at the University of Michigan Medical School, funded by a training grant from the National Institutes of Health to Dr. Benjamin L. Margolis (T35HL007690). This study was supported by a grant to SWC from the National Institutes of Health (1K23AI091623). SWC is an A. Alfred Taubman Institute/Edith Briskin/SKS Foundation Emerging Scholar.

\section{REFERENCES}

1. Ulijaszek SJ, Lofink H. Obesity in biocultural perspective. Annual Review of Anthropology. 2006; 35:337-60. PubMed PMID: WOS:000242032900018. English.

2. Stevens GA, Singh GM, Lu Y, Danaei G, Lin JK, Finucane MM, et al. National, regional, and global trends in adult overweight and obesity prevalences. Popul Health Metr. 2012; 10(1):22. PubMed PMID: 23167948. Pubmed Central PMCID: 3543235. [PubMed: 23167948]

3. Flegal KM, Kit BK, Orpana H, Graubard BI. Association of all-cause mortality with overweight and obesity using standard body mass index categories: a systematic review and meta-analysis. JAMA. Jan 2; 2013 309(1):71-82. PubMed PMID: 23280227. [PubMed: 23280227]

4. Juraschek SP, Miller ER 3rd, Gelber AC. Body mass index, obesity, and prevalent gout in the United States in 1988-1994 and 2007-2010. Arthritis Care Res (Hoboken). Jan; 2013 65(1):127-32. PubMed PMID: 22778033. Pubmed Central PMCID: 3482278. [PubMed: 22778033]

5. Wu CY, Chou YC, Huang N, Chou YJ, Hu HY, Li CP. Association of body mass index with allcause and cardiovascular disease mortality in the elderly. PLoS One. 2014; 9(7):e102589. PubMed PMID: 25014070. [PubMed: 25014070]

6. [7/23/2014] Population-Based Approaches to Childhood Obesity Prevention. http://www.who.int/ dietphysicalactivity/childhood/ WHO_new_childhoodobesity_PREVENTION_27nov_HR_PRINT_OK.pdf

7. [7/23/2014] WHO Factsheet: Obesity and Overweight. http://www.who.int/mediacentre/factsheets/ fs $311 / \mathrm{en} /$

8. Solomon CG, Manson JE. Obesity and mortality: a review of the epidemiologic data. Am J Clin Nutr. Oct; 1997 66(4 Suppl):1044S-50S. PubMed PMID: 9322585. [PubMed: 9322585] 
9. Sorror ML, Martin PJ, Storb R, Bhatia S, Maziarz RT, Pulsipher MA, et al. Pre-transplant comorbidities predict severity of acute graft-versus-host disease and subsequent mortality. Blood. May 5.2014 PubMed PMID: 24797298.

10. Sorror ML. How I assess comorbidities before hematopoietic cell transplantation. Blood. Apr 11; 2013 121(15):2854-63. PubMed PMID: 23355537. Pubmed Central PMCID: 3624933. [PubMed: 23355537]

11. Sorror ML, Maris MB, Storb R, Baron F, Sandmaier BM, Maloney DG, et al. Hematopoietic cell transplantation (HCT)-specific comorbidity index: a new tool for risk assessment before allogeneic HCT. Blood. Oct 15; 2005 106(8):2912-9. PubMed PMID: 15994282. Pubmed Central PMCID: 1895304. [PubMed: 15994282]

12. Aplenc R, Zhang MJ, Sung L, Zhu X, Ho VT, Cooke K, et al. Effect of body mass in children with hematologic malignancies undergoing allogeneic bone marrow transplantation. Blood. May 29; 2014 123(22):3504-11. PubMed PMID: 24711663. [PubMed: 24711663]

13. Barker CC, Agovi MA, Logan B, Lazarus HM, Ballen KK, Gupta V, et al. Childhood obesity and outcomes after bone marrow transplantation for patients with severe aplastic anemia. Biol Blood Marrow Transplant. May; 2011 17(5):737-44. PubMed PMID: 20817111. Pubmed Central PMCID: 3035737. [PubMed: 20817111]

14. Bulley S, Gassas A, Dupuis LL, Aplenc R, Beyene J, Greenberg ML, et al. Inferior outcomes for overweight children undergoing allogeneic stem cell transplantation. Br J Haematol. Jan; 2008 140(2):214-7. PubMed PMID: 18028482. [PubMed: 18028482]

15. Fleming DR, Rayens MK, Garrison J. Impact of obesity on allogeneic stem cell transplant patients: a matched case-controlled study. Am J Med. Mar; 1997 102(3):265-8. PubMed PMID: 9217595. [PubMed: 9217595]

16. Fuji S, Kim SW, Yoshimura K, Akiyama H, Okamoto S, Sao H, et al. Possible association between obesity and posttransplantation complications including infectious diseases and acute graft-versushost disease. Biol Blood Marrow Transplant. Jan; 2009 15(1):73-82. PubMed PMID: 19135945. [PubMed: 19135945]

17. Hadjibabaie M, Tabeefar H, Alimoghaddam K, Iravani M, Eslami K, Honarmand H, et al. The relationship between body mass index and outcomes in leukemic patients undergoing allogeneic hematopoietic stem cell transplantation. Clin Transplant. Jan-Feb;2012 26(1):149-55. PubMed PMID: 21470311. [PubMed: 21470311]

18. Hansen JA, Gooley TA, Martin PJ, Appelbaum F, Chauncey TR, Clift RA, et al. Bone marrow transplants from unrelated donors for patients with chronic myeloid leukemia. N Engl J Med. Apr 2; 1998 338(14):962-8. PubMed PMID: 9521984. [PubMed: 9521984]

19. Le Blanc K, Ringden O, Remberger M. A low body mass index is correlated with poor survival after allogeneic stem cell transplantation. Haematologica. Sep; 2003 88(9):1044-52. PubMed PMID: 12969813. [PubMed: 12969813]

20. Navarro WH, Agovi MA, Logan BR, Ballen K, Bolwell BJ, Frangoul H, et al. Obesity does not preclude safe and effective myeloablative hematopoietic cell transplantation (HCT) for acute myelogenous leukemia (AML) in adults. Biol Blood Marrow Transplant. Oct; 2010 16(10):144250. PubMed PMID: 20412867. Pubmed Central PMCID: 2933950. [PubMed: 20412867]

21. Pine M, Wang L, Harrell FE Jr. Calder C, Manes B, Evans M, et al. The effect of obesity on outcome of unrelated cord blood transplant in children with malignant diseases. Bone Marrow Transplant. Oct; 2011 46(10):1309-13. PubMed PMID: 21151185. [PubMed: 21151185]

22. Sucak GT, Suyani E, Baysal NA, Altindal S, Cakar MK, Aki SZ, et al. The role of body mass index and other body composition parameters in early post-transplant complications in patients undergoing allogeneic stem cell transplantation with busulfancyclophosphamide conditioning. Int J Hematol. Jan; 2012 95(1):95-101. PubMed PMID: 22160835. [PubMed: 22160835]

23. Nikolousis E, Nagra S, Paneesha S, Delgado J, Holder K, Bratby L, et al. Allogeneic transplant outcomes are not affected by body mass index (BMI) in patients with haematological malignancies. Ann Hematol. Nov; 2010 89(11):1141-5. PubMed PMID: 20544351. [PubMed: 20544351]

24. Nakao M, Chihara D, Niimi A, Ueda R, Tanaka H, Morishima Y, et al. Impact of being overweight on outcomes of hematopoietic SCT: a meta-analysis. Bone Marrow Transplant. Jan; 2014 49(1): 66-72. PubMed PMID: 23955636. [PubMed: 23955636] 
25. Choi SW, Kitko CL, Braun T, Paczesny S, Yanik G, Mineishi S, et al. Change in plasma tumor necrosis factor receptor 1 levels in the first week after myeloablative allogeneic transplantation correlates with severity and incidence of GVHD and survival. Blood. Aug 15; 2008 112(4):153942. PubMed PMID: 18502834. Pubmed Central PMCID: 2515125. [PubMed: 18502834]

26. Paczesny S, Krijanovski OI, Braun TM, Choi SW, Clouthier SG, Kuick R, et al. A biomarker panel for acute graft-versus-host disease. Blood. Jan 8; 2009 113(2):273-8. PubMed PMID: 18832652. Pubmed Central PMCID: 2615645. [PubMed: 18832652]

27. Vander Lugt MT, Braun TM, Hanash S, Ritz J, Ho VT, Antin JH, et al. ST2 as a marker for risk of therapy-resistant graft-versus-host disease and death. N Engl J Med. Aug 8; 2013 369(6):529-39. PubMed PMID: 23924003. Pubmed Central PMCID: 3943357. [PubMed: 23924003]

28. Garrow JS, Webster J. Quetelet's index (W/H2) as a measure of fatness. Int J Obes. 1985; 9(2): 147-53. PubMed PMID: 4030199. [PubMed: 4030199]

29. Report of a WHO consultation. Vol. 894. World Health Organ Tech Rep Ser.; 2000. Obesity: preventing and managing the global epidemic.; p. i-xii.p. 1-253.PubMed PMID: 11234459

30. Ogden CL, Flegal KM, Carroll MD, Johnson CL. Prevalence and trends in overweight among US children and adolescents, 1999-2000. JAMA. Oct 9; 2002 288(14):1728-32. PubMed PMID: 12365956. [PubMed: 12365956]

31. Hanauer DA. EMERSE: The Electronic Medical Record Search Engine. AMIA Annu Symp Proc. 2006:941. PubMed PMID: 17238560. Pubmed Central PMCID: 1839699. [PubMed: 17238560]

32. Osuchowski MF, Siddiqui J, Copeland S, Remick DG. Sequential ELISA to profile multiple cytokines from small volumes. J Immunol Methods. Jul; 2005 302(1-2):172-81. PubMed PMID: 16023134. [PubMed: 16023134]

33. Fine JP, Gray RJ. A proportional hazards model for the subdistribution of a competing risk. Journal of the American Statistical Association. Jun; 1999 94(446):496-509. PubMed PMID: WOS: 000081058500019. English.

34. Gray RJ. A Class of K-Sample Tests for Comparing the Cumulative Incidence of a Competing Risk. Annals of Statistics. Sep; 1988 16(3):1141-54. PubMed PMID: WOS:A1988Q161700019. English.

35. Kaplan EL, Meier P. Nonparametric-Estimation from Incomplete Observations. Journal of the American Statistical Association. 1958; 53(282):457-81. PubMed PMID: WOS:A1958WX09300012. English.

36. Bacigalupo A, Ballen K, Rizzo D, Giralt S, Lazarus H, Ho V, et al. Defining the intensity of conditioning regimens: working definitions. Biol Blood Marrow Transplant. Dec; 2009 15(12): 1628-33. PubMed PMID: 19896087. Pubmed Central PMCID: 2861656. [PubMed: 19896087]

37. Hossain P, Kawar B, El Nahas M. Obesity and diabetes in the developing world--a growing challenge. N Engl J Med. Jan 18; 2007 356(3):213-5. PubMed PMID: 17229948. [PubMed: 17229948]

38. Finkelstein EA, Khavjou OA, Thompson H, Trogdon JG, Pan L, Sherry B, et al. Obesity and severe obesity forecasts through 2030. Am J Prev Med. Jun; 2012 42(6):563-70. PubMed PMID: 22608371. [PubMed: 22608371]

39. Prevalence of Self-Reported Obesity Among U.S. Adults. BRFSS; 2012. http://www.cdc.gov/ obesity/data/adult.html\#Prevalence [7/23/2014]

40. Dick AA, Spitzer AL, Seifert CF, Deckert A, Carithers RL Jr. Reyes JD, et al. Liver transplantation at the extremes of the body mass index. Liver Transpl. Aug; 2009 15(8):968-77. PubMed PMID: 19642131. [PubMed: 19642131]

41. Heymsfield SB, Cefalu WT. Does body mass index adequately convey a patient's mortality risk? JAMA. Jan 2; 2013 309(1):87-8. PubMed PMID: 23280230. [PubMed: 23280230]

42. Blouin RA, Warren GW. Pharmacokinetic considerations in obesity. J Pharm Sci. Jan; 1999 88(1): 1-7. PubMed PMID: 9874695. [PubMed: 9874695]

43. Choi S, Reddy P. Graft-versus-host disease. Panminerva Med. Jun; 2010 52(2):111-24. PubMed PMID: 20517195. [PubMed: 20517195]

44. Nikolopoulou A, Kadoglou NP. Obesity and metabolic syndrome as related to cardiovascular disease. Expert Rev Cardiovasc Ther. Jul; 2012 10(7):933-9. PubMed PMID: 22908926. [PubMed: 22908926] 
45. Zeyda M, Wernly B, Demyanets S, Kaun C, Hammerle M, Hantusch B, et al. Severe obesity increases adipose tissue expression of interleukin-33 and its receptor ST2, both predominantly detectable in endothelial cells of human adipose tissue. Int J Obes (Lond). May; 2013 37(5):65865. PubMed PMID: 22828942. [PubMed: 22828942]

46. Martinez-Martinez E, Miana M, Jurado-Lopez R, Rousseau E, Rossignol P, Zannad F, et al. A role for soluble ST2 in vascular remodeling associated with obesity in rats. PLoS One. 2013; 8(11):e79176. PubMed PMID: 24265755. Pubmed Central PMCID: 3827161. [PubMed: 24265755]

47. Vazquez LA, Pazos F, Berrazueta JR, Fernandez-Escalante C, Garcia-Unzueta MT, Freijanes J, et al. Effects of changes in body weight and insulin resistance on inflammation and endothelial function in morbid obesity after bariatric surgery. J Clin Endocrinol Metab. Jan; 2005 90(1):31622. PubMed PMID: 15507518. [PubMed: 15507518]

48. Miller GD, Nicklas BJ, Loeser RF. Inflammatory biomarkers and physical function in older, obese adults with knee pain and self-reported osteoarthritis after intensive weight-loss therapy. $\mathrm{J}$ Am Geriatr Soc. Apr; 2008 56(4):644-51. PubMed PMID: 18312558. [PubMed: 18312558] 


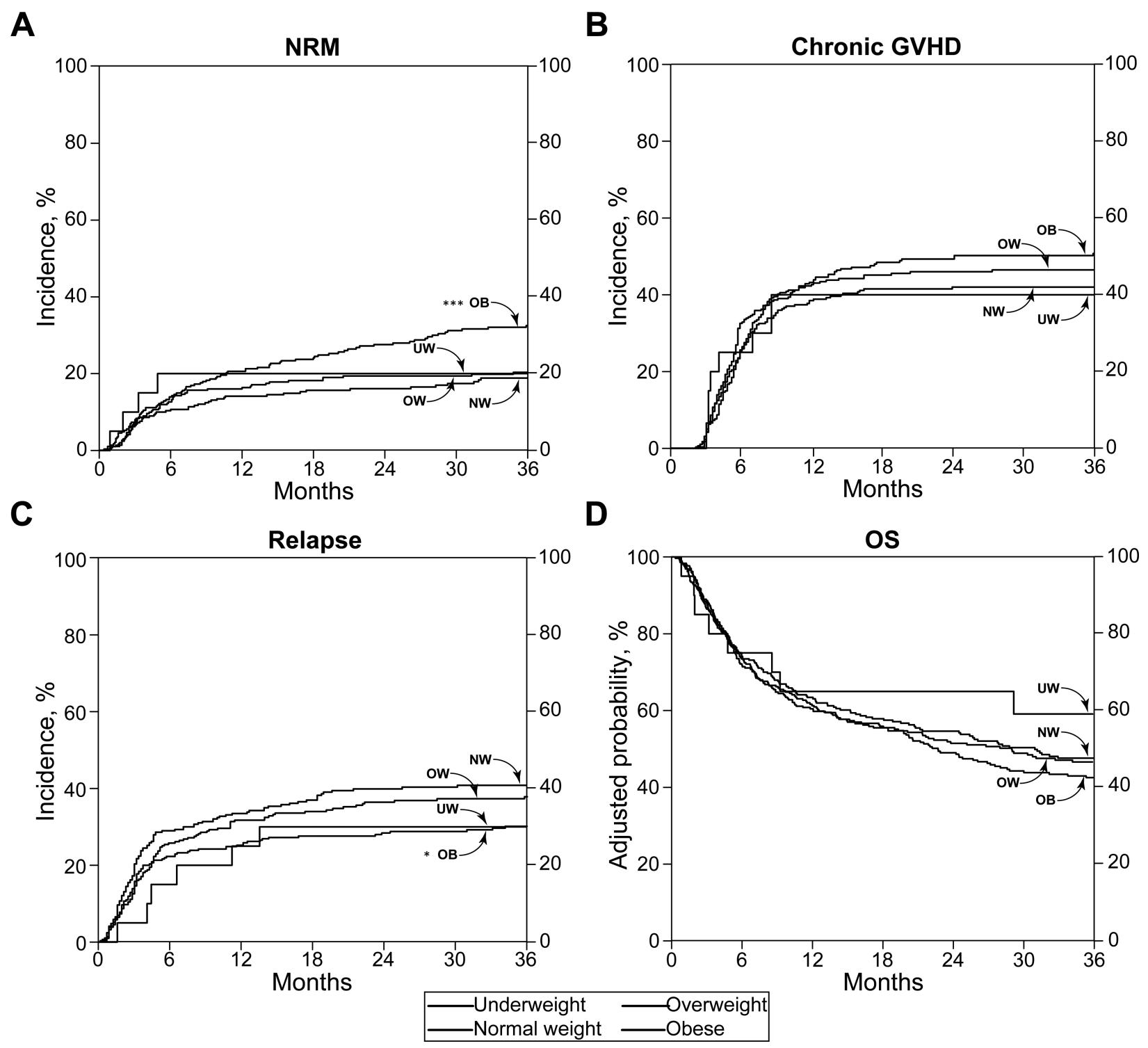

Figure 1. Transplant outcomes by body mass index category

Cumulative incidence of non-relapse mortality, $\mathrm{p}<0.001 * * *$ (A), chronic graft-versus-host disease, $\mathrm{p}=0.07(\mathrm{~B})$, relapse, $\mathrm{p}=0.02 *(\mathrm{C})$, and adjusted probability of overall survival, $\mathrm{p}=0.13$ (D). $\mathrm{N}=20$ underweight (UW), 290 normal weight ( $\mathrm{NW}), 287$ overweight (OW), 301 obese (OB). P-values represent outcomes of obese relative to normal weight patients. 
Table 1

Demographic and transplant characteristics of patients receiving HCT from 2004 to 2012 by BMI category.

\begin{tabular}{|c|c|c|c|c|}
\hline $\mathrm{N}=898$ & UW & NW & OW & OB \\
\hline \multicolumn{5}{|l|}{ Count $(\%)$ or Median (range, interquartile range) } \\
\hline Total & $20(2.2)$ & $290(32.3)$ & $287(32.0)$ & $301(33.5)$ \\
\hline \multicolumn{5}{|l|}{ Age (years) } \\
\hline Pediatric $(<18$ years old $)$ & $8(0.9)$ & $61(6.8)$ & $15(1.7)$ & $17(1.9)$ \\
\hline Adult & $12(1.3)$ & $229(25.5)$ & $272(30.3)$ & $284(31.6)$ \\
\hline \multicolumn{5}{|l|}{ Gender } \\
\hline Male & $10(1.1)$ & $132(14.7)$ & $197(21.9)$ & $201(22.4)$ \\
\hline Female & $10(1.1)$ & $158(17.6)$ & $90(10.0)$ & $100(11.1)$ \\
\hline \multicolumn{5}{|l|}{ Race/ethnicity } \\
\hline White (Non-Hispanic) & $20(2.2)$ & $251(28.0)$ & $268(29.8)$ & $282(31.4)$ \\
\hline All Other & - & $39(4.3)$ & $19(2.1)$ & $19(2.1)$ \\
\hline \multicolumn{5}{|l|}{ Disease } \\
\hline Malignant & $16(1.8)$ & $257(28.6)$ & $279(31.1)$ & $293(32.6)$ \\
\hline Non-Hodgkin lymphoma & $3(0.3)$ & $40(4.5)$ & $52(5.8)$ & $49(5.5)$ \\
\hline Acute myelogenous leukemia & $6(0.7)$ & $89(9.9)$ & $108(12.0)$ & $114(12.7)$ \\
\hline Acute lymphoblastic lymphoma & $2(0.2)$ & $40(4.5)$ & $31(3.5)$ & $45(5.0)$ \\
\hline Myelodysplastic syndrome & - & $17(1.9)$ & $33(3.7)$ & $29(3.2)$ \\
\hline Multiple myeloma & $2(0.2)$ & $18(2.0)$ & $19(2.1)$ & $18(2.0)$ \\
\hline Chronic lymphoblastic lymphoma & $1(0.1)$ & $16(1.8)$ & $14(1.6)$ & $14(1.6)$ \\
\hline Chronic myelogenous leukemia & $1(0.1)$ & $11(1.2)$ & $6(0.7)$ & $6(0.7)$ \\
\hline Myelofibrosis & - & $8(0.9)$ & $6(0.7)$ & $7(0.8)$ \\
\hline Myeloproliferative disorder & $1(0.1)$ & $7(0.8)$ & $6(0.7)$ & $3(0.3)$ \\
\hline Hodgkin lymphoma & - & $8(0.9)$ & $2(0.2)$ & $6(0.7)$ \\
\hline Biphenotypic leukemia & - & $3(0.3)$ & $1(0.1)$ & $2(0.2)$ \\
\hline Histiocytic sarcoma & - & - & $1(0.1)$ & - \\
\hline Non-Malignant & $4(0.4)$ & $33(3.7)$ & $8(0.9)$ & $8(0.9)$ \\
\hline Severe aplastic anemia & $2(0.2)$ & $14(1.6)$ & $4(0.4)$ & $4(0.4)$ \\
\hline Sickle cell disease & - & $8(0.9)$ & - & - \\
\hline Thalassemia & $1(0.1)$ & $2(0.2)$ & $1(0.1)$ & - \\
\hline Familial erythrophagocytic lymphohistiocytosis & - & $2(0.2)$ & - & - \\
\hline Paroxysmal nocturnal hemoglobinuria & - & $1(0.1)$ & $1(0.1)$ & - \\
\hline Severe combined immunodeficiency & - & $2(0.2)$ & - & - \\
\hline Severe congenital neutropenia & - & $1(0.1)$ & $1(0.1)$ & $1(0.1)$ \\
\hline X-linked lymphoproliferative syndrome & - & $1(0.1)$ & $1(0.1)$ & $1(0.1)$ \\
\hline IPEX & - & - & - & - \\
\hline Dyskeratosis congenita & - & $1(0.1)$ & - & $1(0.1)$ \\
\hline Osteopetrosis & $1(0.1)$ & - & - & - \\
\hline Congenital dyserythropoietic anemia & - & $1(0.1)$ & - & - \\
\hline Transplant type/sou & & & & \\
\hline
\end{tabular}




\begin{tabular}{|c|c|c|c|c|}
\hline $\mathrm{N}=\mathbf{8 9 8}$ & UW & NW & ow & OB \\
\hline \multicolumn{5}{|l|}{ Overall } \\
\hline Peripheral blood (PB) & $12(1.3)$ & $217(24.2)$ & $259(28.8)$ & $275(30.6)$ \\
\hline Bone marrow (BM) & $8(0.9)$ & $73(8.1)$ & $28(3.1)$ & $26(2.9)$ \\
\hline \multicolumn{5}{|l|}{ HLA matching and relatedness } \\
\hline Matched Related & $11(1.2)$ & $148(16.5)$ & $130(14.5)$ & $129(14.4)$ \\
\hline Mismatched Related & - & $8(0.9)$ & $10(1.1)$ & $11(1.2)$ \\
\hline Matched Unrelated & $7(0.8)$ & $102(11.4)$ & $107(11.9)$ & $128(14.2)$ \\
\hline Mismatched Unrelated & $2(0.2)$ & $32(3.6)$ & $40(4.5)$ & $33(3.7)$ \\
\hline \multicolumn{5}{|l|}{ Conditioning intensity } \\
\hline Myeloablative & $9(1.0)$ & $182(20.3)$ & $176(19.6)$ & $184(20.5)$ \\
\hline \multicolumn{5}{|l|}{ Total body irradiation $\geq 1200 \mathrm{cGy}$} \\
\hline Yes & $3(0.3)$ & $47(5.2)$ & $30(3.3)$ & $37(4.1)$ \\
\hline No & $6(0.7)$ & $135(15.0)$ & $146(16.3)$ & $147(16.4)$ \\
\hline Reduced Intensity & $11(1.2)$ & $108(12.0)$ & $111(12.4)$ & $117(13.0)$ \\
\hline \multicolumn{5}{|l|}{ HCT-CI } \\
\hline Low & $4(57)$ & $41(35)$ & $35(28)$ & $33(23)$ \\
\hline Intermediate & $1(14)$ & $35(30)$ & $38(30)$ & $43(29)$ \\
\hline High & $2(29)$ & $41(35)$ & $53(42)$ & $71(48)$ \\
\hline \multicolumn{5}{|l|}{ Conditioning Intensity } \\
\hline Myeloablative & $9(1.0)$ & $182(20.3)$ & $176(19.6)$ & $184(20.5)$ \\
\hline \multicolumn{5}{|l|}{ Total body irradiation $\geq 1200 \mathrm{cGy}$} \\
\hline Yes & $3(0.3)$ & $47(5.2)$ & $30(3.3)$ & $37(4.1)$ \\
\hline No & $6(0.7)$ & $135(15.0)$ & $146(16.3)$ & $147(16.4)$ \\
\hline Reduced Intensity & $11(1.2)$ & $108(12.0)$ & $111(12.4)$ & $117(13.0)$ \\
\hline \multicolumn{5}{|l|}{ GVHD prophylaxis } \\
\hline Calcineurin inhibitor + Methotrexate & $10(1.1)$ & $203(22.6)$ & $162(18.0)$ & $188(20.9)$ \\
\hline Calcineurin inhibitor + Mycophenolate mofetil & $9(1.0)$ & $80(8.9)$ & $117(13.0)$ & $106(11.8)$ \\
\hline Calcineurin inhibitor alone & $1(0.1)$ & $2(0.2)$ & $1(0.1)$ & - \\
\hline Other & - & $5(0.6)$ & $7(0.8)$ & $7(0.8)$ \\
\hline \multicolumn{5}{|l|}{ Year of transplant } \\
\hline 2004-2008 & $13(1.4)$ & $168(18.7)$ & $160(17.8)$ & $151(16.8)$ \\
\hline 2009-2013 & $7(0.8)$ & $122(13.6)$ & $127(14.1)$ & $150(16.7)$ \\
\hline
\end{tabular}

*Two patients received bone marrow and related cord blood from the same donor but here categorized as BM.

$\dagger$ In one peripheral blood transplant the donor's gender was not disclosed.

$\ddagger^{\mathrm{W}}$ (wild) refers to any non-negative CMV result: + , equivocal or unknown.

IPEX - immunodysregulation polyendocrinopathy enteropathy X-linked syndrome.

HCT-CI - Hematopoietic cell transplantation Comorbidity Index. Available for underweight $(n=7)$, normal weight $(n=117)$, overweight $(n=126)$, obese $(\mathrm{n}=147)$ 


\section{Table 2}

Clinical outcomes by BMI category.

\begin{tabular}{|c|c|c|c|c|}
\hline & UW & NW & ow & OB \\
\hline \multicolumn{5}{|l|}{ Count $(\%)$ or Median (range, IQR) } \\
\hline Total & 20 & $290(34.5)$ & $287(32.0)$ & $301(33.5)$ \\
\hline Follow-up time (months) & $29.4(0.8-113.7,7.6-64.4)$ & $18.9(0.5-117.7,5.7-50.0)$ & $17.8(0.3-117.6,5.4-49.9)$ & $17.8(0.6-115.5,5.9-43.4)$ \\
\hline Hospital length of stay (days) & $29(18-68,24-35)$ & $24(12-175,21-29)$ & $23(0-154,20-27)$ & $23(0-98,21-26)$ \\
\hline \multicolumn{5}{|l|}{ Acute GVHD ${ }^{*}$} \\
\hline Yes & $9(1.0)$ & $159(17.7)$ & $174(19.4)$ & $178(19.8)$ \\
\hline 1 & - & $42(4.7)$ & $50(5.6)$ & $36(4.0)$ \\
\hline 2 & $4(0.4)$ & $69(7.7)$ & $64(7.1)$ & $76(8.5)$ \\
\hline 3 & $4(0.4)$ & $24(2.7)$ & $25(2.8)$ & $32(3.6)$ \\
\hline 4 & $1(0.1)$ & $24(2.7)$ & $35(3.9)$ & $34(3.8)$ \\
\hline No & $11(1.2)$ & $131(14.6)$ & $113(12.6)$ & $123(13.7)$ \\
\hline \multicolumn{5}{|l|}{ Chronic GVHD } \\
\hline Yes & $9(1.0)$ & $135(15.0)$ & $148(16.5)$ & $166(18.5)$ \\
\hline No & $11(1.2)$ & $155(17.3)$ & $139(15.5)$ & $135(15.0)$ \\
\hline \multicolumn{5}{|l|}{ Relapse } \\
\hline Yes & $6(0.7)$ & $116(12.9)$ & $107(11.9)$ & $91(10.1)$ \\
\hline No & $14(1.6)$ & $174(19.4)$ & $180(20.0)$ & $210(23.4)$ \\
\hline \multicolumn{5}{|l|}{ Survival } \\
\hline Alive & $10(1.1)$ & $133(14.8)$ & $122(13.6)$ & $116(12.9)$ \\
\hline Dead & $10(1.1)$ & $157(17.5)$ & $165(18.4)$ & $185(20.6)$ \\
\hline \multicolumn{5}{|l|}{ Causes of Death } \\
\hline Relapse & $4(40.0)$ & $99(63.1)$ & $91(55.2)$ & $76(41.1)$ \\
\hline Acute GVHD & $2(20.0)$ & $26(16.6)$ & $36(21.8)$ & $35(18.9)$ \\
\hline Chronic GVHD & $2(20.0)$ & $20(12.7)$ & $27(16.4)$ & $57(30.1)$ \\
\hline Graft rejection or failure & - & $2(1.3)$ & $3(1.8)$ & $2(1.1)$ \\
\hline Idiopathic pneumonia syndrome & - & - & $1(0.6)$ & $7(3.8)$ \\
\hline Infection $^{\dagger}$ & $1(10.0)$ & $2(1.3)$ & $3(1.8)$ & $2(1.1)$ \\
\hline Hepatic veno-occlusive disorder & - & $1(0.6)$ & $1(0.6)$ & $3(1.6)$ \\
\hline Engraftment syndrome & - & - & $1(0.6)$ & $1(0.5)$ \\
\hline Cardiac event & - & $1(0.6)$ & $1(0.6)$ & - \\
\hline PTLD & - & $1(0.6)$ & - & - \\
\hline Pulmonary hypertension & - & $1(0.6)$ & - & - \\
\hline Small bowel obstruction & - & - & - & $1(0.5)$ \\
\hline Accidental trauma & - & - & - & $1(0.5)$ \\
\hline Other ${ }^{+}$or unknown & $1(10.0)$ & $4(2.5)$ & $1(0.6)$ & - \\
\hline
\end{tabular}

PTLD - post-transplant lymphoproliferative disorder.

* Acute GVHD onset day $₫ 00$ post-transplant and not post-relapse, max grade shown.

Bone Marrow Transplant. Author manuscript; available in PMC 2015 March 05. 
${ }^{\dagger}$ Among deaths from infection, one UW patient died from Pneumocystis jirovecii pneumonia, one NW patient from human herpes virus 6 meningoencephalitis, one NW, two OW and one OB patients from culture-negative sepsis, one OW patient from pneumonia of unknown etiology, and one OB patient from a bacterial infection at another hospital.

Fone UW patient died from esophageal cancer; three NW patients died from lung cancer. 
Table 3

Results of multivariate regression analysis by BMI category.

\begin{tabular}{|c|c|c|c|}
\hline & $\mathbf{N}$ & HR $(95 \%$ CI $)$ & $p$ value \\
\hline \multicolumn{4}{|l|}{ aGVHD } \\
\hline \multicolumn{4}{|l|}{ BMI } \\
\hline Normal & 290 & 1.00 & - \\
\hline UW & 20 & $1.11(0.56-2.21)$ & 0.76 \\
\hline Ow & 287 & $1.03(0.78-1.35)$ & 0.85 \\
\hline OB & 301 & $1.15(0.89-1.50)$ & 0.29 \\
\hline \multicolumn{4}{|l|}{ Other covariates } \\
\hline Continuous age & 898 & $1.00(0.99-1.00)$ & 0.37 \\
\hline \multicolumn{4}{|l|}{ Malignancy } \\
\hline Non-malignant & 53 & 1.00 & - \\
\hline Malignant & 845 & $1.73(0.82-3.68)$ & 0.15 \\
\hline \multicolumn{4}{|l|}{ Relatedness } \\
\hline Related & 447 & 1.00 & - \\
\hline Unrelated & 451 & $1.88(1.50-2.35)$ & $<0.001$ \\
\hline \multicolumn{4}{|l|}{ Transplant type } \\
\hline PB & 763 & 1.00 & - \\
\hline $\mathrm{BM}$ & 135 & $0.66(0.44-0.99)$ & 0.04 \\
\hline \multicolumn{4}{|l|}{ HLA match } \\
\hline Matched & 762 & 1.00 & - \\
\hline Mismatched & 136 & $1.69(1.30-2.17)$ & $<0.001$ \\
\hline \multicolumn{4}{|c|}{ Conditioning intensity } \\
\hline Myeloablative & 551 & 1.00 & - \\
\hline Reduced & 347 & $1.19(0.94-1.49)$ & 0.14 \\
\hline \multicolumn{4}{|l|}{ Year of transplant } \\
\hline 2004-2008 & 492 & 1.00 & - \\
\hline $2008-2013$ & 406 & $0.76(0.61-0.95)$ & 0.02 \\
\hline \multicolumn{4}{|l|}{ cGVHD } \\
\hline \multicolumn{4}{|l|}{ BMI } \\
\hline Normal & 290 & 1.00 & - \\
\hline UW & 20 & $0.99(0.46-2.12)$ & 0.98 \\
\hline OW & 287 & $1.07(0.83-1.38)$ & 0.60 \\
\hline OB & 301 & $1.21(0.94-1.55)$ & 0.14 \\
\hline \multicolumn{4}{|l|}{ Other covariates } \\
\hline Continuous age & 898 & $1.00(0.99-1.01)$ & 0.69 \\
\hline \multicolumn{4}{|l|}{ Malignancy } \\
\hline Non-malignant & 53 & 1.00 & - \\
\hline Malignant & 845 & $1.29(0.72-2.31)$ & 0.38 \\
\hline \multicolumn{4}{|l|}{ Relatedness } \\
\hline Related & 447 & 1.00 & - \\
\hline
\end{tabular}

Bone Marrow Transplant. Author manuscript; available in PMC 2015 March 05. 


\begin{tabular}{|c|c|c|c|}
\hline & $\mathbf{N}$ & HR $(95 \%$ CI $)$ & $p$ value \\
\hline Unrelated & 451 & $1.13(0.92-1.39)$ & 0.23 \\
\hline \multicolumn{4}{|l|}{ Transplant type } \\
\hline $\mathrm{PB}$ & 763 & 1.00 & - \\
\hline BM & 135 & $0.91(0.61-1.36)$ & 0.65 \\
\hline \multicolumn{4}{|l|}{ HLA match } \\
\hline Matched & 762 & 1.00 & - \\
\hline Mismatched & 136 & $0.95(0.73-1.25)$ & 0.73 \\
\hline \multicolumn{4}{|c|}{ Conditioning intensity } \\
\hline Myeloablative & 551 & 1.00 & - \\
\hline Reduced & 347 & $1.02(0.82-1.27)$ & 0.82 \\
\hline \multicolumn{4}{|l|}{ Year of transplant } \\
\hline 2004-2008 & 492 & 1.00 & - \\
\hline 2008-2013 & 406 & $0.96(0.79-1.17)$ & 0.70 \\
\hline \multicolumn{4}{|l|}{ NRM } \\
\hline \multicolumn{4}{|l|}{ BMI } \\
\hline Normal & 290 & 1.00 & - \\
\hline UW & 20 & $1.74(0.76-4.01)$ & 0.19 \\
\hline OW & 287 & $0.95(0.65-1.37)$ & 0.77 \\
\hline OB & 301 & $1.43(1.02-2.01)$ & 0.04 \\
\hline \multicolumn{4}{|l|}{ Other covariates } \\
\hline Continuous age & 898 & $1.01(1.00-1.02)$ & 0.18 \\
\hline \multicolumn{4}{|l|}{ Malignancy } \\
\hline Non-malignant & 53 & 1.00 & - \\
\hline Malignant & 845 & $0.37(0.10-1.33)$ & 0.13 \\
\hline \multicolumn{4}{|l|}{ Relatedness } \\
\hline Related & 447 & 1.00 & - \\
\hline Unrelated & 451 & $2.20(1.65-2.94)$ & $<0.001$ \\
\hline \multicolumn{4}{|l|}{ Transplant type } \\
\hline $\mathrm{PB}$ & 763 & 1.00 & - \\
\hline BM & 135 & $0.23(0.09-0.58)$ & 0.002 \\
\hline
\end{tabular}

HLA match

$\begin{array}{lrrr}\text { Matched } & 762 & 1.00 & - \\ \text { Mismatched } & 136 & 1.59(1.16-2.22) & 0.004\end{array}$

Conditioning intensity

Myeloablative

$551 \quad 1.00$

Reduced

$347 \quad 1.02(0.76-1.35)$

0.91

Year of transplant

2004-2008

2008-2013

406

$0.79(0.60-1.05)$

0.10

Relapse

BMI

Normal

290

1.00 


\begin{tabular}{|c|c|c|c|}
\hline & $\mathbf{N}$ & HR $(95 \% \mathrm{CI})$ & $p$ value \\
\hline UW & 20 & $0.70(0.32-1.50)$ & 0.36 \\
\hline ow & 287 & $0.79(0.61-1.03)$ & 0.08 \\
\hline OB & 301 & $0.65(0.49-0.86)$ & 0.002 \\
\hline \multicolumn{4}{|l|}{ Other covariates } \\
\hline Continuous age & 898 & $1.00(1.00-1.01)$ & 0.36 \\
\hline \multicolumn{4}{|l|}{ Malignancy } \\
\hline Non-malignant & 53 & 1.00 & - \\
\hline Malignant & 845 & $26.50(3.49-201.02)$ & 0.002 \\
\hline \multicolumn{4}{|l|}{ Relatedness } \\
\hline Related & 447 & 1.00 & - \\
\hline Unrelated & 451 & $0.61(0.48-0.77)$ & $<0.001$ \\
\hline \multicolumn{4}{|l|}{ Transplant type } \\
\hline PB & 763 & 1.00 & - \\
\hline BM & 135 & $1.09(0.72-1.66)$ & 0.68 \\
\hline \multicolumn{4}{|l|}{ HLA match } \\
\hline Matched & 762 & 1.00 & - \\
\hline Mismatched & 136 & $0.83(0.60-1.18)$ & 0.29 \\
\hline \multicolumn{4}{|c|}{ Conditioning intensity } \\
\hline Myeloablative & 551 & 1.00 & - \\
\hline Reduced & 347 & $0.90(0.69-1.16)$ & 0.42 \\
\hline \multicolumn{4}{|l|}{ Year of transplant } \\
\hline 2004-2008 & 492 & 1.00 & - \\
\hline $2008-2013$ & 406 & $0.76(0.60-0.95)$ & 0.02 \\
\hline
\end{tabular}

OS

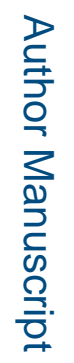

BMI

Normal

290

1.00

UW

OW

OB

$20 \quad 1.02(0.54-1.95)$

0.95

287

0.85 (0.68-1.07)

0.17

Other covariates

Continuous age

301

$0.93(0.75-1.16)$

0.55

Malignancy

Non-malignant

898

$1.01(1.00-1.02)$

0.003

Malignant

$\begin{array}{rrr}53 & 1.00 & - \\ 845 & 2.05(0.92,4.58) & 0.08\end{array}$

Relatedness

Related

Unrelated

451

$1.24(1.03-1.49)$

0.02

Transplant type

PB

763

1.00

$\mathrm{BM}$

135

$0.56(0.38-0.82)$

0.003

HLA match

Matched

762

1.00

Bone Marrow Transplant. Author manuscript; available in PMC 2015 March 05. 


\begin{tabular}{crrr}
\hline & $\mathbf{N}$ & HR $(\mathbf{9 5 \%}$ CI) & $\boldsymbol{p}$ value \\
\hline Mismatched & 136 & $1.41(1.12-1.79)$ & 0.003 \\
Conditioning intensity & & & \\
Myeloablative & 551 & 1.00 & - \\
Reduced & 347 & $0.89(0.74-1.09)$ & 0.24 \\
Year of transplant & & & \\
2004-2008 & 492 & 1.00 & - \\
$2008-2013$ & 406 & $0.78(0.65-0.94)$ & 0.01 \\
\hline
\end{tabular}


Table 4

Baseline levels of plasma biomarker ST2 by BMI category.

\begin{tabular}{lrrr}
\hline BMI category & $\mathbf{N}$ & Median concentration (IQR), pg/ml & $\boldsymbol{p}$-value \\
\hline Normal & 115 & $131(0-628)$ & - \\
UW & 7 & $256(82-659)$ & 0.51 \\
OW & 115 & $208(0-845)$ & 0.22 \\
OB & 110 & $257(0-1045)$ & 0.04 \\
\hline
\end{tabular}


Table 5

Baseline levels of plasma biomarker TNFR1 by BMI category.

\begin{tabular}{lrrr}
\hline BMI category & N & Median concentration (IQR), pg/ml & $\boldsymbol{p}$-value \\
\hline Normal & 88 & $2129(1486-3232)$ & - \\
UW & 7 & $1596(1467-2971)$ & 0.57 \\
OW & 81 & $2266(1708-3725)$ & 0.32 \\
OB & 99 & $2644(1922-3395)$ & 0.05 \\
\hline
\end{tabular}

